\title{
A moradia estudantil universitária como tema na produção científica nacional
}

\author{
Edleusa Nery Garrido \\ Elizabeth Nogueira Gomes da Silva Mercuri
}

\begin{abstract}
Resumo
O estudo teve como propósito realizar uma análise da produção científica nacional sobre moradias estudantis universitárias. Foram consultadas as principais bases de dados nacionais e sítios eletrônicos de diversas instituições brasileiras de ensino superior. Localizaram-se 23 estudos, publicados entre 2000 e 2009. O resultado da análise dos objetivos das produções apontou diferentes focos, agrupados em três categorias: o estudante morador, a moradia estudantil e as ações da assistência estudantil. Embora haja ampla produção científica estrangeira voltada ao estudo das moradias universitárias, a nacional ainda é escassa e a visão da moradia como espaço de formação está pouco presente. Sugeremse investigações que busquem conhecer a realidade desses ambientes e os impactos produzidos sobre os estudantes. Tendo em vista que as moradias estudantis são de responsabilidade institucional, acredita-se que tais estudos possam subsidiar medidas que garantam adequadas condições de formação do universitário.
\end{abstract}

Palavras-chave: Atividades extracurriculares, ensino superior; estudantes universitários.

\section{College student residence halls as a theme in the national scientific production}

\begin{abstract}
This study analyses the national scientific production about college students' residence halls. The country's main data bases and electronic sites of several Brazilian higher education institutions were checked and 23 studies, published between 2000 and 2009 , were found. The results of our analysis point to different focuses, which can be grouped into three categories: students who live in residence halls, residence halls themselves and actions for student assistance. Although there is large foreign scientific production about college student housing, the national production on this theme is still scarce, and the idea of student residence halls as educational spaces is still very incipient. The study points out to the need for investigating the living conditions in these places, and the impacts of this kind of habitation on students. Considering that student housing is an institutional responsibility, these studies potentially subsidize measures for proper educational conditions for college students.
\end{abstract}

Key words: Extracurricular activities, higher education, college students.

\section{La vivienda estudiantil universitaria como tema en la producción científica nacional}

\section{Resumen}

El objetivo de este estudio fue realizar un análisis de la producción científica nacional sobre viviendas estudiantiles universitarias. Se consultaron las principales bases de datos nacionales y sitios electrónicos de diversas instituciones brasileñas de enseñanza superior. Se ubicaron 23 estudios publicados entre 2000 e 2009. El resultado del análisis de los objetivos de las producciones presentó diferentes focos, agrupados en tres categorías: el estudiante morador, la vivienda estudiantil y las acciones de la asistencia estudiantil. No obstante exista amplia producción científica extranjera dedicada al estudio de las viviendas universitarias, la nacional aún es escasa y la visión de la vivienda como espacio de formación está poco presente. Sugerimos investigaciones que busquen conocer la realidad de estos ambientes y los impactos producidos sobre los estudiantes. Dado que las viviendas estudiantiles son de responsabilidad institucional se considera que tales estudios puedan subsidiar medidas que garanticen adecuadas condiciones de formación del universitario.

Palabras clave: Actividades extracurriculares, educación superior, estudiantes universitarios. 


\section{Introdução}

A vivência acadêmica envolve o conjunto de experiências que os estudantes do ensino superior têm durante os anos de formação em ambiente acadêmico institucional ou a ele vinculado. No geral, abarca desde as atividades obrigatórias, tais como aulas em classes e laboratórios e os estágios, até aquelas de caráter não obrigatório, embora também relacionadas à formação. Como atividade não obrigatória, é possível citar: iniciação científica; atividades esportivas e artísticas; frequência ao restaurante da instituição; grupos de estudos; participação em eventos de natureza acadêmica e científica, como seminários e congressos; representação estudantil, dentre outros.

Tem destaque no presente artigo o papel das atividades não obrigatórias que, na literatura acadêmica, se encontram associadas a diferentes expressões, como: atividade extraclasse, atividade extramuros, atividade extracurricular ou atividade fora da sala de aula. Todas têm em comum o fato de oferecer experiências diversificadas e de caráter não obrigatório para estudantes de um mesmo curso (Fior \& Mercuri, 2003).

De acordo com pesquisas realizadas (Capovilla \& Santos, 2001; Fior \& Mercuri, 2003; Kuh, 1995; Terenzini, Pascarella, \& Blimling, 1996), tanto as atividades obrigatórias quanto as optativas exercem impacto expressivo sobre a formação do estudante. Kuh (1995) conduziu pesquisa exploratória com estudantes de onze instituições de ensino superior dos Estados Unidos, com o propósito de identificar a contribuição das experiências extraclasse na aprendizagem e no desenvolvimento pessoal dos estudantes. Os resultados indicaram ganhos em competência interpessoal, competência prática, conhecimentos e habilidades acadêmicas, aumento da complexidade cognitiva e do humanitarismo. Também nos Estados Unidos, Terenzini e cols. (1996) efetuaram revisão de literatura com o objetivo de examinar a influência das experiências extraclasse sobre a aprendizagem dos estudantes da educação superior e concluíram que as experiências fora da sala de aula exercem mais influência no desenvolvimento acadêmico e intelectual dos estudantes do que pensam professores e administradores.

No Brasil, Capovilla e Santos (2001) realizaram uma pesquisa com estudantes do curso de odontologia de uma universidade particular no interior do Estado de São Paulo, com o objetivo de identificar a frequência de participação desses estudantes em atividades extramuros, bem como avaliar a influência destas em seu desenvolvimento pessoal. As principais atividades extramuros identificadas foram: conversar com os professores em espaço extraclasse, realizar estágios na área profissional, morar em alojamento estudantil, envolver-se em atividades voluntárias, participar de projetos de pesquisa, de clubes e organizações estudantis. Os resultados mostraram que a influência das atividades extramuros sobre os estudantes ocorreu de forma acentuada nos seguintes aspectos do desenvolvimento: altruísmo, autoconfiança, aplicação de conhecimentos, autonomia, noção de propósito, raciocínio reflexivo, competência social, com- petência vocacional e aquisição de conhecimento. De forma menos acentuada foram observados impactos sobre competência e habilidades acadêmicas e apreciação cultural.

Fior e Mercuri (2003) investigaram as contribuições das atividades não obrigatórias para as mudanças pessoais do estudante universitário de uma universidade pública do Estado de São Paulo. Os estudantes mencionaram a participação em uma ampla gama de atividades não exigidas no currículo obrigatório, entre as quais é possível citar: participar de monitorias, estágios extracurriculares, grupos de estudo, discussões e debates entre estudantes, atividades artísticas e culturais, empresa júnior, centros estudantis e residir na moradia estudantil. As autoras identificaram que o número de alterações, mudanças ou consequências pessoais percebidas pelos estudantes como associadas à participação em atividades não obrigatórias é bastante extenso e, apesar de, em sua maioria, poderem ser consideradas como impactos positivos na formação e no desenvolvimento do estudante, algumas delas são consideradas como impactos negativos, a exemplo do empobrecimento dos hábitos alimentares e da acentuação do egoísmo.

Observa-se que, tanto no estudo de Capovilla e Santos (2001) quanto no realizado por Fior e Mercuri (2003), os estudantes identificaram, entre as atividades não obrigatórias, a experiência de residir em moradia estudantil como uma vivência acadêmica que propicia mudança ou alterações pessoais. Esse dado é convergente com os resultados de diversas pesquisas realizadas nos Estados Unidos sobre o impacto da moradia estudantil na formação do estudante.

Em uma abrangente revisão de literatura, Pascarella e Terenzini (1991) analisaram o impacto das instituições de ensino superior sobre o estudante e, entre outras temáticas exploradas nos estudos sobre formação dos estudantes que residiam em moradias localizadas dentro do campus, constataram uma série de mudanças expressivas - decorrentes daquela experiência - em vários aspectos, tais como: alterações em valores intelectuais, culturais e estéticos; liberalização de atitudes e de valores religiosos, políticos e sociais; desenvolvimento do autoconceito, da orientação intelectual, da autonomia e independência; tolerância; empatia; habilidades para lidar com outras pessoas e uso do princípio da razão para julgar questões de natureza moral. Concluíram também que residir no campus aumentou significativamente a probabilidade de os estudantes persistirem nos estudos, assim como de concluí-los. Em nova revisão de literatura realizada em 2005, com o mesmo propósito, esses autores confirmaram os achados da revisão de 1991 e, além disso, concluíram que a experiência de morar no campus, independentemente do tipo de moradia, promove atitudes etnorraciais mais positivas e inclusivas, assim como leva o estudante a uma maior abertura à diversidade, quando comparado com seus pares que moram fora do campus e se deslocam até ele (Pascarella \& Terenzini, 2005).

Yeung (2009) efetuou um estudo cuja finalidade foi a de identificar o impacto da experiência de morar em residências situadas no campus sobre o rendimento médio do estudante e sobre sua integração acadêmica e social. O tipo 
de residência foi categorizado como: moradia no campus, residência com os familiares e outros espaços de moradias. O autor concluiu que morar no campus exerce influência positiva na integração acadêmica e social do estudante, enquanto morar com os familiares exerce ligeira influência positiva sobre o desempenho acadêmico.

Com o propósito de aprofundar a compreensão sobre a relação entre tipo de moradia dos estudantes e desempenho acadêmico, Turley e Wodtke (2010) compararam o rendimento médio de estudantes que moravam dentro do campus com mais três grupos de estudantes: aqueles que moravam fora com suas famílias, aqueles que moravam fora sem a família e aqueles que viviam em outros tipos de residência. Os autores verificaram que, em alguns grupos de estudantes, morar em residências dentro do campus causa impacto mais expressivo sobre o desempenho acadêmico: estudantes negros que viviam dentro do campus apresentaram desempenho acadêmico mais elevado, quando comparados com seus colegas também negros que viviam fora com suas famílias.

A despeito do considerável número de pesquisas nos Estados Unidos sobre moradias estudantis e dos resultados de seu impacto na formação dos estudantes, no Brasil investigações sobre o tema ainda são raras. O presente estudo teve como propósito fazer uma análise da produção científica nacional que versa sobre moradias estudantis universitárias. Buscou-se sistematizar e discutir as subtemáticas presentes nos objetivos dos estudos levantados. Compreendendo a experiência de viver em uma moradia estudantil durante os anos de graduação como uma atividade não obrigatória que pode ser enriquecedora da formação do estudante, buscou-se verificar se essa concepção se faz presente na literatura encontrada. A moradia estudantil aqui considerada é aquela sob a responsabilidade total ou parcial de uma instituição de ensino superior, voltada para acomodar estudantes regularmente matriculados e localizada dentro ou fora do campus.

\section{Delineamento do estudo}

No período de março de 2009 a dezembro de 2010, foram consultadas as bases de dados da Scientific Electronic Library Online (Scielo), da Biblioteca Virtual em Saúde (BVS), da Literatura Latino-Americana e do Caribe em Ciências da Saúde (LILACS), da Red de Revistas Cientificas de América Latina y El Caribe, España y Portugal (Redalyc) e da Plataforma do Currículo Lattes, com as seguintes palavras-chave: moradia estudantil, residência estudantil, residência estudantil universitária, alojamento, alojamento estudantil, casa do(a) estudante, casa do(a) estudante universitário(a), república estudantil e assistência estudantil. Em complemento, examinaram-se os sítios eletrônicos de diversas instituições de ensino superior de todas as regiões do Brasil.

As subtemáticas presentes nos objetivos dos estudos foram identificadas a partir da Análise de Conteúdo (Bardin, 1977/2009). Procurou-se verificar também o entendimento dos autores sobre a importância da moradia estudantil na formação do estudante.

\section{Resultados e discussão}

A literatura nacional encontrada, totalizando $23 \mathrm{pu}-$ blicações, está assim distribuída: quatro livros, um capítulo de livro, cinco dissertações de mestrado, nove artigos publicados em revistas científicas, três trabalhos completos apresentados em evento de natureza científica e um texto publicado no formato de noticiário em revista científica. Quanto ao ano de publicação, os estudos datam de 2000 até 2009, e 14 deles compreendem o período de 2006 a 2009.

A análise dos objetivos das publicações apontou para diferentes temáticas que puderam ser agrupadas em três principais categorias: o estudante morador, a moradia estudantil e a assistência estudantil.

A primeira categoria concentra cerca de metade da produção e seu foco é o estudante morador. As análises voltam-se para aspectos a ele relacionados, como sua saúde; os processos de socialização no ambiente da moradia; a noção de territorialidade em uma moradia estudantil, bem como o nível de privacidade percebido pelos estudantes nesses espaços; o discurso dos moradores sobre o consumo de drogas; o perfil pessoal, acadêmico e político dos estudantes; suas perspectivas de emprego e/ou de estudo após a conclusão do curso de graduação; suas formas de participação política no ambiente acadêmico; e sua trajetória escolar.

Na segunda categoria, composta de seis publicações, a atenção dos autores se dirige às moradias. Tais estudos resgatam principalmente o histórico desses locais. Apenas uma produção teve por objetivo descrever um programa em funcionamento na moradia estudantil focalizada.

A terceira categoria engloba quatro produções dirigidas à análise da assistência aos estudantes prestada pelas universidades e abrange também o programa de moradia estudantil.

A seguir serão apresentados e discutidos os objetivos dos estudos enquadrados em cada uma dessas três categorias e de acordo com as subtemáticas identificadas.

\section{O estudante morador: subtemáticas vinculadas}

É possível destacar neste grupo de estudos a preocupação com a saúde dos estudantes que vivem em moradias estudantis. O artigo de Alves e Boog (2007) teve como objetivo descrever o comportamento alimentar dos estudantes de uma moradia estudantil de um município no estado de São Paulo. O olhar das autoras voltou-se para a educação alimentar, com vistas à promoção da saúde dos estudantes. Miranda, Amorim e Stancato (2007), por sua vez, apresentaram uma proposta de censo, a fim de conhecer a saúde dos estudantes residentes na moradia estudantil da Universidade Estadual de Campinas. Zalaf (2007) e Zalaf e Fonseca (2009) também trouxeram a saúde dos estudantes como elemento norteador de suas pesquisas, ao analisarem o uso de álcool e outras drogas entre moradores do Conjunto Residencial da Universidade de São Paulo (CRUSP). A 
pesquisa teve como objetivo conhecer como se deu o processo saúde-doença dos participantes, seu modo de vida e as formas de enfrentamento das dificuldades presentes na moradia estudantil.

Aspectos relacionados à socialização dos estudantes no ambiente da moradia foi outra subtemática encontrada em alguns estudos. Laranjo (2003) e Laranjo e Soares (2006) tiveram como propósito investigar como se desenvolvem os processos de socialização entre os estudantes residentes da moradia estudantil de uma universidade do estado de São Paulo. Na Universidade Federal do Paraná, Berlatto e Sallas (2008) realizaram pesquisa etnográfica em uma moradia estudantil voltada para o público feminino, com o objetivo de verificar as formas de sociabilidade construídas no ambiente da moradia e o modo como essas relações contribuíam para a reconstrução da subjetividade das moradoras. Em outro estudo efetuado sobre o mesmo espaço, Martins (2002) teve como propósito investigar o processo de individualização das estudantes residentes durante as décadas de 1950 e 1960 a partir de fontes documentais e entrevistas com ex-moradoras. A pesquisa de Sousa (2005) com os estudantes residentes nas moradias estudantis da Universidade Federal de Goiás e da Universidade Católica de Goiás buscou apreender os significados e os sentidos da moradia estudantil para eles, tendo em vista o contexto social em que estavam inseridos e a forma como ocorriam as relações cotidianas dentro das casas.

Em Brasília, Paiva e Mendes (2002) utilizaram o aporte da psicologia ambiental para averiguar quais eram os comportamentos e as percepções sobre territorialidade e privacidade dos moradores da Casa do Estudante Universitário da Universidade de Brasília. Tanto as características do ambiente físico quanto do social foram consideradas como variáveis que influenciavam os aspectos examinados.

A preocupação com o uso de drogas entre estudantes da educação superior também se faz presente nos estudos sobre o estudante residente em moradia estudantil. Ao considerar as dificuldades decorrentes dos processos de adaptação à universidade e à moradia estudantil, o que poderia levar os estudantes ao consumo de drogas e à depressão, Laranjo (2003) e Laranjo e Soares (2006) buscaram apreender o discurso dos moradores sobre o consumo de drogas no ambiente da moradia de uma universidade do estado de São Paulo.

O estudo de Araújo e Morgado (2007) indiretamente faz certa aproximação entre a experiência de viver em uma moradia estudantil e os resultados educacionais. As autoras investigaram como o conjunto das ações de assistência estudantil impacta positivamente os estudantes, incluindo aí a condição de ser residente em uma moradia estudantil. $O$ objetivo não foi o de avaliar a assistência estudantil em si, mas sua influência sobre os estudantes. Para isso, as autoras delinearam o perfil pessoal, acadêmico e político dos estudantes atendidos por diversas ações da assistência estudantil, incluindo a moradia. Esses estudantes dependiam de tais ações para permanecerem na universidade.
Outro estudo desenvolvido por Araújo e Morgado em 2008 teve como propósito verificar quais eram as perspectivas de emprego e/ou de estudo dos estudantes, prováveis formandos dos semestres 2007/2 e 2008/1, moradores da Casa do Estudante Universitário da Universidade Federal de Mato Grosso no campus de Cuiabá. As autoras se ampararam na perspectiva de que a moradia estudantil foi uma das ações que garantiram a permanência e a conclusão da graduação dos sujeitos entrevistados.

As formas de participação política dos estudantes residentes em moradias estudantis no ambiente acadêmico foram trazidas por Lima (2002), que registrou em artigo uma intervenção realizada com os estudantes do programa de moradia estudantil da Universidade Federal de Pernambuco. A atividade relatada teve como propósito instigar a mobilização e a participação dos residentes para lutar por seus direitos, assim como para buscar soluções para os problemas cotidianos.

A investigação realizada por Rosa (2008) enfatizou a trajetória escolar dos estudantes de graduação de vários cursos de prestígio, em momento anterior ao vestibular. Os participantes da pesquisa residiam na moradia estudantil da Universidade Federal do Rio Grande do Sul. O autor teve como objetivo compreender os efeitos das origens sociais no acesso à universidade.

O conjunto de trabalhos que traz o estudante como foco de estudo reúne uma diversidade de subtemáticas relevantes e contribui para o entendimento de aspectos relacionados ao estudante da educação superior, notadamente os que vivem em moradias estudantis. Investigar a saúde dos estudantes, por exemplo, é de grande importância, uma vez que a falta ou a má qualidade desta pode ser um elemento impeditivo da aprendizagem.

Pesquisadores estrangeiros têm se voltado para estudos sobre a saúde desse segmento da população estudantil: ao tomar como sujeitos de pesquisa residentes em moradias estudantis nos Estados Unidos, Dusselier, Dunn, Wang, Shelley e Whalen (2005) encontraram associação de problemas com companheiros de quarto, dificuldades para estudar no espaço da residência e ruído elevado com o aumento no nível de estresse dos estudantes. Na França, foram identificadas diversas queixas de estudantes relacionadas às condições das moradias estudantis, que, por sua vez, foram associadas a implicações para a saúde desses sujeitos (Shaikh \& Deschamps, 2006). O conhecimento de aspectos que impactam negativamente a saúde dos estudantes pode fornecer subsídios que orientem ações preventivas de morbidades e promotoras da saúde por parte tanto das instituições responsáveis pelas moradias estudantis quanto de seus moradores.

As demais subtemáticas apresentadas nos estudos, como vimos, tratam principalmente de aspectos relacionados ao ambiente social do estudante e ao seu percurso escolar durante os anos de graduação. No que diz respeito ao ambiente social, os autores consideraram apenas a característica de coletividade presente no ambiente da moradia. Já nos estudos que tratam da trajetória acadêmica dos 
estudantes, o foco de atenção dos autores se voltou para o impacto da assistência como um todo, o que não permite um olhar sobre a especificidade da condição de morador perante as questões discutidas.

Em alguns dos objetivos dos trabalhos analisados, o impacto produzido nos estudantes a partir da experiência de viver em moradia estudantil apareceu de uma forma mais direta. Alves e Boog (2007) relacionaram tal condição com mudança nos hábitos alimentares; Laranjo (2003) e Laranjo e Soares (2006) consideraram a influência do viver em moradia sobre o processo de socialização dos estudantes, bem como sobre a percepção destes em relação ao consumo de drogas; Berlatto e Sallas (2008) investigaram os processos de sociabilidade presentes no ambiente da moradia como elemento de reconstrução da subjetividade das moradoras; Martins (2002), por sua vez, verificou de que forma a experiência das estudantes na condição de moradoras interferiu na construção da sua identidade feminina; Paiva e Mendes (2002) relacionaram as interações sociais à ocupação e ao uso do espaço físico da moradia, bem como à percepção que os estudantes tinham sobre tal dinâmica. Nos demais estudos, não houve associação direta entre viver em moradia estudantil e sua influência sobre o estudante.

Considera-se que as subtemáticas discutidas nesta categoria de estudos são relevantes, pois ajudam a entender como certas características ou condições da moradia produzem impacto sobre o estudante. Todavia, essas considerações não têm sido elaboradas a partir de uma perspectiva da moradia como espaço de formação. Nos textos examinados, notou-se a ausência de uma discussão mais vigorosa que considerasse a experiência de viver em uma moradia estudantil como parte da vivência acadêmica dos estudantes e que relacionasse tal experiência com o processo de formação mais ampla dos estudantes.

Nos Estados Unidos o olhar de muitos pesquisadores sobre a moradia estudantil está fortemente voltado para sua dimensão pedagógica, e os resultados de diversas pesquisas sobre o assunto têm destacado a importância desta. $O$ impacto positivo da interação entre pares, especialmente no espaço das moradias, e sua relação com a formação geral é discutido por Levine (1994), Pascarella e Terenzini (2005), Pascarella, Terenzini e Blimling (1994), e a interação entre pares, por sua vez, está relacionada a uma maior abertura para a diversidade (Pascarella, 2006; Pike, 2002). Enochs e Roland (2006) constataram que estudantes do sexo masculino que residiam em moradias estudantis apresentaram níveis de adaptação social e geral mais elevados do que suas colegas, em mesmas condições. Devlin, Donovan, Nicolov, Nold e Zandan (2008) identificaram diferenças significativas no senso de comunidade dos estudantes em função do desenho arquitetônico das residências em que viviam. O impacto positivo da experiência de viver numa moradia estudantil sobre a persistência nos estudos foi investigado por Jacobs e Archie (2008), Pascarella, Terenzini e Blinlimg, (1994) e Yeung (2009).

\section{A moradia estudantil: subtemáticas vinculadas}

O segundo grupo de produções encontrado é direcionado à moradia estudantil, e tem como subtemática principal o resgate de suas histórias. Machado contribui com três publicações: um breve histórico sobre as repúblicas estudantis de Ouro Preto (Machado, 2003); um texto no qual apresenta um panorama geral sobre o surgimento de algumas moradias estudantis no contexto nacional (Machado, 2007); e uma publicação organizada em 2008, desta vez detalhando o histórico das diversas repúblicas de Ouro Preto e Mariana (Machado, 2008). Souza $(2006,2009)$, a partir de fontes documentais e relatos de ex-moradores, reconstituiu parte da história da Casa do Estudante Universitário do Paraná, atualmente conveniada com a Universidade Federal do Paraná (Andrich, 2007). Um esforço com vistas ao mesmo objetivo foi empreendido por Vilela Jr. (2003), que buscou trazer, ainda que em breve relato, a história do alojamento estudantil da Universidade de Brasília.

A raridade de publicações sobre a origem das diversas moradias estudantis existentes no País põe em evidência, principalmente, a necessidade de uma maior atenção para os registros institucionais sobre objetivos e concepções com que essas moradias são criadas e quais circunstâncias e atores estão envolvidos no processo.

A outra subtemática existente nos estudos focados na moradia estudantil reporta à análise de programas em funcionamento no interior da moradia estudantil. Com esse objetivo foi identificado apenas o Na Boca do CRUSP Programa de Prevenção e Acolhimento do Uso de Álcool e Outras Drogas, publicado por Zalaf e Fonseca (2007).

Diversas pesquisas norte-americanas têm se voltado para a análise do impacto que programas em execução nos ambientes das moradias exercem sobre o estudante morador. Em 2004 uma investigação nacional naquele país, denominada National Study of Living-Learning Programs (NSLLP), identificou 274 programas em funcionamento. O estudo buscou examinar a relação entre tais programas e alguns aspectos dos estudantes, como a transição acadêmica, o crescimento intelectual, a valorização da diversidade, o engajamento cívico, o consumo de álcool, a permanência na universidade e a satisfação com a universidade (Inkelas \& Longerbeam, 2008). A iniciativa de Zalaf e Fonseca (2007) instiga à realização de pesquisas com vistas a investigar o funcionamento de programas e outras ações desenvolvidas nos ambientes das moradias estudantis, por iniciativa institucional ou dos próprios moradores.

Além da questão dos programas disponíveis nas moradias estudantis, pouco também se conhece sobre as características desses espaços, por exemplo: quais são as condições de estudos existentes; qual a oferta de atividades esportivas e de lazer; como a ocupação por quarto ou dormitório é pensada e de que forma isso afeta o estudante. Nos Estados Unidos, Li, Maximova, Saunders, Whalen e Shelley (2007) alertam para a necessidade de verificar os fatores presentes nas moradias estudantis que contribuem para a satisfação dos estudantes nas instituições de educação 
superior, uma vez que esta é um importante precursor para o desenvolvimento pessoal e para a integração social dos estudantes moradores.

\section{A assistência estudantil como foco: subtemáticas vinculadas}

O terceiro conjunto de textos localizados está voltado à assistência estudantil, e o programa de moradia aparece como parte das análises das ações desse tipo de assistência. Neste grupo se encontram as dissertações de Rocha (2000) e de Araújo (2003), assim como os artigos de Araújo e Morgado (2008) e Rosa (2008). Alguns estudos trazem uma análise da assistência estudantil como um todo, e em outros a subtemática presente é o impacto dessa assistência sobre o estudante.

Rocha (2000) investigou a assistência estudantil por meio das representações e das práticas sociais dos próprios usuários da Universidade Federal de Alagoas. Já Araújo (2003) desenvolveu sua pesquisa na Universidade Federal de Pernambuco. Essa autora fez a análise da assistência estudantil, considerando o direito à educação e à assistência estudantil, inclusive o programa de moradia estudantil, e comparou os resultados dessa análise com o desempenho dos estudantes assistidos.

O estudo realizado por Araújo e Morgado (2008, p. 2) na Universidade Federal de Mato Grosso teve o intuito de "desvelar o significado das ações de assistência estudantil para os estudantes assistidos e [...] as perspectivas de emprego/e ou estudo desses estudantes após a conclusão dos cursos de graduação". Tanto no estudo desenvolvido por Araújo (2003) quanto no de Araújo e Morgado (2008) os sujeitos entrevistados foram os estudantes residentes das moradias estudantis das respectivas instituições.

A pesquisa realizada por Rosa (2008), já citada no grupo de subtemáticas referente ao estudante, trouxe como segundo objetivo relacionar as condições de manutenção dos estudantes residentes dentro da instituição universitária com a política de assistência estudantil. Em outras palavras, o autor também investigou os recursos institucionais voltados para a assistência estudantil disponíveis aos estudantes.

Estudos com o propósito de avaliar as ações da assistência estudantil fornecem às instâncias competentes importantes subsídios para correções dos programas existentes ou ainda para orientar a implantação de novas iniciativas. No entanto, ao avaliar a assistência estudantil no seu conjunto, deixa-se de aprofundar a relação entre diversos aspectos da formação dos estudantes com as especificidades de cada uma das ações existentes.

\section{Considerações finais}

A revisão da literatura nacional sobre moradias estudantis mostrou uma diversidade de subtemáticas presentes nos objetivos dos estudos que são voltados ou para o estudante morador, ou para a moradia, ou ainda para a assistência estudantil, que tem como parte de sua tarefa o programa de moradia. No entanto, conclui-se que a concepção predominante sobre moradias estudantis, veiculada na produção científica nacional, no conjunto das ações da assistência estudantil, é a de ser um local com finalidade única de alojar e de garantir a permanência dos estudantes até a finalização de seus estudos.

Incorporar em pesquisas futuras a compreensão de moradia estudantil como um espaço educacional é imprescindível, uma vez que a literatura estrangeira e parte da nacional têm apontado resultados expressivos do impacto que a vivência em moradia estudantil exerce sobre diversos aspectos da formação dos estudantes. Identifica-se um potencial campo de investigações que aprofundem essa relação, considerando variáveis como o tipo de moradia, características físicas do ambiente, programas existentes, o número de moradores, composição quanto ao gênero, às características das políticas públicas em relação à moradia (como, por exemplo, os critérios para ocupação das vagas), entre outras. O conhecimento gerado deverá propiciar não só um diálogo com a literatura disponível em outros contextos, como também suportes para tomada de decisões sobre as características desejáveis a uma moradia estudantil.

A importância e a necessidade de estudos sobre moradias estudantis e seus moradores ficam justificadas nas disposições legais atuais sobre a assistência ao estudante. Em se tratando das instituições de ensino superior de categoria administrativa pública, por exemplo, a legislação em vigor realça e incentiva as responsabilidades institucionais nas ações de assistência. No âmbito federal, o Decreto $n^{\circ}$ 7.234/2010 atualizou a Portaria Normativa n 39/2007, que dispõe sobre o Programa Nacional de Assistência Estudantil - PNAES (2010). No âmbito estadual, a Portaria Normativa $n^{\circ}$ 25/2010 dispõe sobre o Programa Nacional de Assistência Estudantil para as Instituições de Educação Superior Públicas Estaduais (PNAEST). As instituições estaduais que participam do Sistema de Seleção Unificada (SISU) passarão a contar com recursos do governo federal para a promoção de ações voltadas à assistência estudantil (2010). Em ambos os documentos, a moradia estudantil aparece como o primeiro item das ações de assistência.

Espera-se que esta revisão possa sensibilizar e direcionar os envolvidos nessa questão - pesquisadores, administradores ou profissionais de assistência ao estudante - para o potencial papel da moradia estudantil como um espaço institucional de formação do estudante do ensino superior. Tendo em vista que a maior parte da literatura disponível sobre moradias estudantis é estrangeira e, como tal, baseia-se em características e problemas que podem diferir daqueles encontrados no contexto nacional, há necessidade de investimento em estudos e ações que possam fornecer elementos norteadores à adoção de medidas que contribuam para o enriquecimento da vivência acadêmica dos estudantes brasileiros em suas moradias estudantis. 


\section{Referências}

Alves, H. J., \& Boog, M. C. (2007). Comportamento alimentar em moradia estudantil: um espaço para promoção da saúde. Revista de Saúde Pública, 41(2), 97-204.

Andrich, M. (2007, 4 de janeiro). Convênio pode salvar Casa do Estudante. Paraná Online. Recuperado: 27 Nov. 2008. Disponível: http://www.parana-online.com.br

Araújo, J. O. (2003). O Elo Assistência e educação: análise assistência/desempenho no Programa Residência Universitária Alagoana. Dissertação de Mestrado, Programa de Pós-Graduação em Serviço Social, Universidade Federal de Pernambuco.

Araújo, D., \& Morgado, M. A. (2007). Educação e juventude: um panorama da assistência estudantil e de seus usuários na UFMT (Cuiabá). Anais do XIV Encontro Nacional da Abrapso. Rio de Janeiro, RJ. Recuperado: 20 ago. 2008. Disponível: http://www. abrapso.org.br

Araújo, D., \& Morgado, M. A. (2008) Universidade e assistência estudantil: perspectivas de jovens moradores da CEU-UFMT (Campus Cuiabá). Seminário Interno sobre Educação. Cuiabá, MT. Recuperado: 15 Out. 2009. Disponível: http://www.ie.ufmt.br

Bardin, L. (2009). Análise de conteúdo. (L. E. Reto \& A. Pinheiro, Trad.) Lisboa: Edições 70. (Trabalho original publicado em 1977)

Berlatto, F., \& Sallas, A. L. F. (2008). Um lar em terra estranha: espaço e sociabilidade em uma casa de estudantes feminina. Revista Chilena de Antropologia Visual, 2(2). Recuperado: 09 Fev. 2009. Disponível: http://www.antropologiavisual.cl/\#

Capovilla, S. L., \& Santos, A. A. A. (2001). Avaliação da influência de atividades extramuros no desenvolvimento pessoal de universitários. Psico-USF, 6(2), 49-58.

Decreto $n^{\circ}$ 7.234. (2010, 19 de julho). Dispõe sobre o Plano Nacional de Assistência Estudantil (PNAES). Recuperado: 25 Fev. 2011. Disponível: http://www.planalto.gov.br

Devlin, A. S., Donovan, S., Nicolov, A., Nold, O., \& Zandan, G. (2008). Residence hall architecture and sense of community. Environment and Behavior. 40(4), 487-521.

Dusselier, L., Dunn, B., Wang, Y., Shelley, M. C., \& Whalen, D. F. (2005). Personal, health, academic, and environmental predictors of stress for residence hall students. Journal of American College Health, 54(1), 15-24.

Enochs, W. K., \& Roland, C. B. (2006). Social adjustment of college freshmen: the importance of gender and living environment. College Student Journal, 40(1), 63-73.

Fior, C., \& Mercuri, E. (2003). Formação universitária: o impacto das atividades não obrigatórias. Em E. Mercuri, \& S. Polydoro
(Org.), Estudante universitário: características e experiências de formação (pp. 129-154). Taubaté, SP: Cabral Editora e Livraria Universitária.

Inkelas, K. K., \& Longerbeam, S. (2008). Working toward a comprehensive typology of living-learning programs. Em G. Luna \& J. Gahagan (Ed.), Learning initiatives in the residential setting (pp. 29-41). Columbia: National Resource Center for the First-Year Experience \& Student in Transition.

Jacobs, J., \& Archie, T. (2008). Investigating sense of community in first-year college students. Journal of Experiential Education, 30(3), 282-285.

Kuh, G. (1995). The other curriculum: out-of-class experiences associated with student learning and personal development. The Journal of Higher Education, 66(2),123-155.

Laranjo, T. H. (2003). O CRUSP: processo de socialização e consumo de drogas. Dissertação de mestrado, Escola de Enfermagem, Universidade de São Paulo.

Laranjo, T. H., \& Soares, C. (2006). Moradia universitária: processos de socialização e consumo de drogas. Revista de Saúde Pública, 40(6), 1027-1034

Levine, A. G. (1994). Education in residential life. Em C. Schroeder \& P. Mable (Orgs.), Realizing the Educational potential of Residence Halls (pp.93-106). San Francisco, Califórnia: Jossey Bass.

Li, L., Maximova, E., Saunders, K., Whalen, D., \& Shelley, M. (2007). The influence of custodial, maintenance, and residence life services on student satisfaction in residence halls. Journal of College and University Student Housing, 34(2), 43-52.

Lima, C. P. (2002). A arte da participação e a participação pela arte: uma experiência nas casas de estudantes universitárias da UFPE. Serviço Social em Revista, 5(1), Recuperado 18 Mar. 2009. Disponível: http://www.ssrevista.uel.br/c_v5n1_carla.htm

Machado, O. L. (2003). As repúblicas estudantis da Universidade Federal de Ouro Preto, Brasil. Revista Crítica de Ciências Sociais, 66, 197-199.

Machado, O. L. (2007). Casas de estudantes e educação superior no Brasil. Em M. Zaidan Filho \& O. L. Machado (Orgs.), Movimento Estudantil Brasileiro e a Educação Superior (pp. 191-208). Recife: Editora Universitária.

Machado, O. L. (2008). Repúblicas de Ouro Preto e Mariana. Projeto A engenharia nacional, os estudantes e a educação superior: a memória reabilitada (1930-1985). Recife: Universidade Federal de Pernambuco. Recuperado: 10 Fev. 2010. Disponível: http:// republicasdaufop.blogspot.com

Martins, A. P. V. (2002). Um lar em terra estranha: a casa da estudante universitária de Curitiba e o processo de individualização feminina 
nas décadas de 1950 e 1960. Curitiba: Aos Quatro Ventos.

Miranda, E. J., Amorim, M., \& Stancato, K. (2007). Educação em saúde em moradia universitária: abordagem integral da vulnerabilidade dos sujeitos. Avaliação - Revista de Avaliação da Educação Superior, 12(2), 349-371.

Paiva, D., \& Mendes, G. (2002). Onde se pode ficar nu: territorialidade e privacidade na casa do estudante universitário da UNB. Textos do laboratório de psicologia ambiental, 6. Recuperado: 02 Fev. 2009. Disponível: http://www.psi-ambiental.net

Pascarella, E. (2006). How College Affects Students: Ten Directions for Future Research. Journal of College Student Development, 47(5), 508-520.

Pascarella, E., \& Terenzini, P. (1991). How college affects students: Findings and insights from twenty years of research. San Francisco: Jossey-Bass.

Pascarella, E., \& Terenzini, P. (2005). How college affects students: A third decade of research. San Francisco: Jossey-Bass.

Pascarella, E., Terenzini, P., \& Blimling, G. (1994). The impact of residential life on students. EM C. Schroeder. \& P. Mable (Orgs.), Realizing the educational potential of residence halls (pp.22-52). San Francisco, Califórnia: Jossey Bass.

Pike, G. (2002). The differential effects of on-and off-campus living arrangements on students' openess to diversity. NASPA Journal, 39(4), 283-299.

Portaria Normativa MEC $n^{\circ}$ 25. (2010). Dispõe sobre o Programa Nacional de Assistência Estudantil para as Instituições de Educação Superior Públicas Estaduais (PNAEST). Recuperado: 25 Fev. 2011. Disponível: http://www.jusbrasil.com.br

Rocha, S. (2000). Assistência ao estudante Universitário: representações sociais e práticas no espaço acadêmico. Dissertação de mestrado, Centro de Ciências Sociais Aplicadas, Universidade Federal de Pernambuco.

Rosa, E. (2008). Os trajetos escolares dos graduandos das Casas de Estudante da Universidade Federal do Rio Grande do Sul e sua origem social. Revista Espaço Acadêmico, 89. Recuperado: 09 Fev. 2009. Disponível: http://www.espacoacademico.com. br/089/89rosa.pdf
Shaikh, B., \& Descamps, J. P. (2006). Life in a university residence: issues, concerns and responses. Education for Health, 19(1), 4351.

Sousa, L. (2005). Significados e sentidos das casas estudantis: um estudo com jovens universitários. Dissertação de mestrado, Programa de Pós-Graduação em Psicologia, Universidade Católica de Goiás.

Souza, E. (2006). História da Casa do Estudante Universitário do Paraná. Quatro Barras, PR: Protexto.

Souza, E. (2009). A 'CEU' ontem e hoje. Curitiba: Contexto.

Terenzini, P. T., Pascarella, E., \& Blimling, G. S. (1996). Students' outof-class experiences and their influence on learning and cognitive development. Journal of College Student Development, 37(2), $149-162$.

Turley , R. N., \& Wodtke, G. (2010). College Residence and Academic Performance: Who Benefits From Living on Campus? Urban Education, 45(4). Recuperado: 11 Mai. 2011. Disponível: http:// uex.sagepub.com

Vilela Jr., A. J. (2003). Uma visão sobre alojamentos universitários no Brasil. Anais do V Seminário Docomomo Brasil. São Carlos, São Paulo. Recuperado: 05 Fev. 2009. Disponível: http://www. docomomo.org.br

Yeung, R. (2009). A quasi-experimental approach to estimating the impact of Collegiate Housing. Annual Appam Research Conference, 31. Washington, DC. Recuperado: 09 Dez. 2009. Disponível: https://www.appam.org

Zalaf, M. R. (2007). Uso problemático de álcool e outras drogas em moradia estudantil: conhecer para enfrentar. Dissertação de mestrado, Programa de Pós-Graduação em Saúde Coletiva, Universidade de São Paulo.

Zalaf, M. R., \& Fonseca, R. M. G. (2007). Na boca do CRUSP: programa de prevenção e acolhimento em caso de uso problemático e drogas. Escola Anna Nery, 11(4), 650-654.

Zalaf, M. R., \& Fonseca, R. M. G. (2009). Uso de álcool e outras drogas em moradia estudantil: conhecer para enfrentar. Revista Escola de Enfermagem da USP, 43(1), 132-138. 
Recebido em: 05/12/2011

Reformulado em: 09/06/2012

Aprovado em: 08/10/2012

\section{Sobre as autoras}

Edleusa Nery Garrido (edleusagarrido@gmail.com)

Doutoranda pela Faculdade de Educação da Universidade Estadual de Campinas. Professora Assistente da Universidade do Estado da Bahia, Campus II. Rodovia Alagoinhas - Salvador BR 110, Km 03 - Alagoinhas, Bahia. CEP: 48.040-210.

Elizabeth Nogueira Gomes da Silva Mercuri. (emercuri@unicamp.br)

Doutora em Educação. Professora Colaboradora da Faculdade de Educação da Universidade Estadual de Campinas. Avenida Bertrand Russell, 801, Cidade Universitária Zeferino Vaz, Campinas, São Paulo. CEP 13083-865.

Este artigo é uma versão ampliada da Comunicação Científica intitulada A Moradia Estudantil Universitária: uma análise da produção científica nacional, apresentada no X CONGRESSO NACIONAL DE PSICOLOGIA ESCOLAR E EDUCACIONAL, realizado nos dias 03 a 06 de julho de 2011, na Universidade Estadual de Maringá, em Maringá - PR. 
